\title{
ЭКОЛОГИЧЕСКАЯ МОДЕРНИЗАЦИЯ ПРОМЫШЛЕННОГО ПРОИЗВОДСТВА
}

\author{
(c) 2021 Вейг Наталья Васильевна
}

кандидат экономических наук, доцент, докторант

кафедра экономики и управления предприятиями и производственными комплексами Санкт-Петербургский государственный экономический университет, Россия, Санкт-Петербург

E-mail: veyg_natalia@mail.ru

\section{(c) 2021 Аврора Матеос Родригес}

соискатель, кафедра экономики и управления предприятиями и производственными комплексами Санкт-Петербургский государственный экономический университет, Россия, Санкт-Петербург

E-mail: auroramateos@yahoo.com

В статье рассматриваются вопросы развития теории экологической модернизации промышленного производства. Анализируется соотношение технологической и экологической модернизации. Высказывается мнение о невозможности проведения экологической модернизации промышленного производства рыночными методами и признается значительная роль государственного регулирования экологической модернизации в достижении целей устойчивого развития.

Ключевые слова: устойчивые технологии, модернизация, экологическая модернизация, устойчивое развитие

Современное развитие социальноэкономических систем различного уровня управления все более и более реализуется как устойчивое развитие, при этом приобретающее характер экологического вектора. Значимость реализации данного направления обуславливается глобальными проблемами экологии и климатических изменений, непосредственно затрагивающих практически все территории планеты, в том числе Мировой океан. При этом все чаще и чаще используется термин «экологическая модернизация», хотя, как мы показывали в ряде предыдущих работ даже само понятие «модернизация» еще не получило общепризнанного значения, равно как и «модернизация производства». Единственное, что можно однозначно сказать, что это приведение параметров производства (продукции, услуг и др.) в соответствии с современными требованиями к объекту производства.

Традиционно под модернизацией производства понимается замена и усовершенствование производственного аппарата предприятия, в первую очередь оборудования, внедрение новых технологий, использование новых и модифицированных материалов. В последнее десятилетие значительное внимание уделяется модернизации производства на основе реализации цифровых инструментов. Тем не менее, существует сфера, предполагающая модернизацию нема- териальной составляющей функционирования промышленных предприятия. Это относится и к модернизации менеджмента предприятия, что включает не только изменения в структуре персонала предприятия, изменения структуры менеджмента с точки зрения функциональной направленности, но и повышение квалификации а также переподготовку для развития владения новыми технологиями В то же время следует уделить внимание экологическому аспекту модернизации производства, о котором много и давно говорят и пишут, однако активная деятельность в этом направление началась сравнительно недавно, в том числе по причинам о которых будет сказано ниже. Не вдаваясь в определенные подробности, следует отметить, что в научной литературе существует (и достаточно давно) множество определений термина «экологическая модернизация». Так, И.П.Кулясов трактует «экологическую модернизацию» как «изменения в соответствии с новейшими, современными экологическими требованиями и нормами, выполнение которых ведет к устранению проблем между человеком и окружающей средой, обществом и природой» [1]. В ряде докладов конференции ««Экологическая модернизация России: роль науки и гражданского общества» «экологическая модернизация» предстает как «изменение экологической политики государства, в результате которой будут достигнуты, по 
крайней мере, три основных результата: повышение качества жизни, повышение экономической эффективности и обеспечение «зеленого роста» экономики и энергетики, и сохранение и восстановление природной среды» [2]. При этом, по отдельности каждая составляющая правомерна, упоминание же всех сразу вносит некоторый диссонанс. В интересной работе Г.Э.Кудиновой, А. Г. Розенберг, Г. С. Розенберг [3] также представлен обзор ряда понятий экологической модернизации.

В ряде работ [4] экологическая модернизация описывается только как технологический подход, непосредственно ориентированный на экологические инновации. Практически это и позволило впоследствии создать экономические сегменты, использующие экологически чистые технологий. Эта концепция часто ассоциируется с экологически эффективными инновациями, а именно с внедрением экологически чистых технологий за счет повышения производительности ресурсов. Так, определение ОЭСР сосредоточено на предотвращении ущерба окружающей среде: «Экологические технологии - методы и технологии, способные сокращать ущерб окружающей среде за счет процессов и материалов, которые вырабатывают меньше потенциально опасных веществ, извлекать такие вещества из выбросов перед их сбросом, либо утилизировать и перерабатывать отходы производства»*. Тем не менее, несмотря на преимущества устойчивых технологий в рамках экологической модернизации, следует упомянуть и о недостатках последних [5]:

- большинство этих технологий далеки от масштаба, при котором замена традиционных видов топлива становится эффективной;

- устойчивые технологии, как правило, значительно дороже, чем традиционные, т.е. нуждаются в субсидиях, налоговых льготах, квотировании доли рынка, выступая как определенная нагрузка на государственный (региональный) бюджет;

- проблемы, обусловленные незрелостью технологии, невозможностью или ограничением масштабируемости, несовместимость (неполная совместимость) с существующей развитой инфраструктурой;

- рост доли таких технологий требует значительных капитальных вложений, что негатив- но отразится на стоимости энергии, и как следствие на покупательной способности населения.

Экологическую модернизацию можно разглядеть и в радикальных инновациях в области устойчивых (чистых) технологий за счет оптимизации использования материалов, энергии, транспорта, пространства и продуктов. Как писал М.Янике две вещи являются движущей силой экологической модернизации, а именно роль «умного» государственного регулирования и рост рисков для бизнеса в связи с загрязнением в контексте многоуровневого управления окружающей средой. Дополнительно, Mol, Arthur P. J., and Gert Spaargaren (2000) [6] показывают, что теория экологической модернизации не должна приводить к деиндустриализации. Это еще раз подчеркивается определением экологической модернизации как процесса коренного техникотехнологического обновления производства, характеризующегося снижением природоемкости экономики. В настоящее время потребляется значительно больше природных ресурсов, чем планета может восстановить за год. По данным Global Footprint Network, за первые семь месяцев 2018 года была израсходована годовая норма такого ресурса как вода, а природных ресурсов и экосистемных услуг используется так, как если бы у нас было 1,7 Земли [7].

Глобализация также сыграла определенную роль в этом контексте, особенно в рамках оценки влияния экономического роста, что также вызывает экологические диспропорции между развитыми и развивающимися странами. Последнее зависит от институционализации экологических воззрений в глобальных организациях, связанных с использованием природных ресурсов периферийными государствами, и стремления повысить прозрачность экологической политики. Экологическая модернизация традиционно рассматривается как основа устойчивого развития и используется правительствами при разработке национальной политики развития, в частности сохранение ресурсов и переработка отходов, реализуются в рамках государственной политики. При этом правительства становятся заинтересованными лицами, что, собственно, и является одной из целей экологической модернизации. В то же время, на наш взгляд, экологическая модернизация не является самоцелью, но лишь определяет условия проведения техноло-

\footnotetext{
* ОЭСР использует ссылку из Глоссария по статистике окружающей среды, Исследования по методам, серия F, № 67. Нью-Йорк: Организация Объединенных Наций.
} 
гической модернизации на различных уровнях управления социально-экономическими системами (предприятием, корпорацией, регионом, отраслью, экономикой государства).

Таким образом, технологическая модернизация промышленного производства является приматом по сравнению с экологической модернизацией, представляющей собой граничные условия ее реализации, определяющих целесообразность (социально-экономическую) и достаточность с точки зрения минимально допустимого воздействия на окружающую среду. При этом рассматривать возможности (последствия) экологической модернизации следует не только в рамках экологической составляющей частных проектов модернизации промышленного производства, но в рамках совокупности отраслевых технологических систем. Нужно отметить, что это отразилось и в ряде определений понятия экологической модернизации. Так, например, S.Cohen (2000) характеризует экологическую модернизацию как термин, описывающий тенденции научно-технического развития в контексте экологических проблем по согласованию ответственности за воздействие на окружающую с экономическим ростом. Howes et al. (2010) трактуют понятие экологической модернизации в контексте формирования ее общих принципов как основы достижения необходимой политической цели государственных структур и субъектов хозяйственной деятельности [8]. В этом же издании приводится мнение Mol (2001) о том, что «исследования ЭМ отражают то, как различные учреждения и социальные субъекты пытаются интегрировать экологические проблемы в свое повседневное функционирование», хотя делается закономерный вывод, что правительства и рынки сосредоточены на раз- личных приоритетах.

Экологическая модернизация в контексте устойчивого развития, не только на наш взгляд, еще не нашла экономической системы, к которой она может легко адаптироваться. Капитализм, как показывает история и все нарастающие по последствиям кризисы, оказался неустойчивой системой, в которой социальная политика не играет доминирующую роль, а охрана окружающей среды не является приоритетом. Как отметил Foster J. (2002) [9] в книге «Экология против капитализма», последний не может обеспечить решение экологических проблем, поскольку он распыляет общество, где люди борются друг с другом и игнорируют потребности друг друга. Он считает, что активное накопление продуктов в нашем обществе (в том числе в результате технологической модернизации) просто несовместимо с окружающей средой:

«Труд и земля рассматриваются как товары. Люди делятся на производителей и потребителей. Желание товаров считается ненасытным. Свобода сужается до права выбора между конкурирующими альтернативами ...» [9]. В то же время для достижения устойчивого развития необходима определенная степень командной экономики, чтобы установить пределы дикого производства или потребления и выдвинуть на первый план социальную политику. На данный момент можно утверждать, что рыночная экономика в ее примитивном понимании никогда не ставит благополучие планеты на первое место, а «невидимая» рука рынка не защитит окружающую среду. Таким образом, экологическая модернизация должна регулироваться на всех уровнях управления от субъекта хозяйствования до субъектов управления на федеральном уровне, в том числе и нерыночными методами.

\section{Библиографический список}

1. Кулясов И.П. Экологическая модернизация: теоретические аспекты // Социология и социальная антропология. 2005. № 3. с. 100-113.

2. http://www.ms-green.ru/actuals/argp.litml7cmdfl77J4-163-13527

3. Кудинова Г.Э., Розенберг А.Г., Розенберг Г. С. Экологическая модернизация: становление, современное состояние, перспективы// Самарская Лука: проблемы региональной и глобальной экологии. 2013.- Т. 22, № 2.- C. 5-26.

4. Janicke, $M$ (1992) Conditions for environmental policy success: an international comparison in Jachtenfuchs, M and Strubel, M (Eds.) Environmental Policy in Europe: Assessment, Challenges and Perspectives, Baden-Baden: Nomos Verlagsgesellschaft, 71-91

5. Gülen, G. (2011) Defining, Measuring and Predicting Green Jobs.: Copenhagen Consensus Center. p. 26.

6. Mol, Arthur P. J., and Gert Spaargaren. 2000. “Ecological Modernization. Theory in Debate: A Review.” Pp. 17-49 
7. Technology can help us save the planet. But more than anything, we must learn to value nature. https://www. weforum.org/agenda/2018/08/here-s-how-technology-can-help-us-save-the-planet/

8. Glynn P, Cadman T., Maraseni T. Ecological modernization: theory and the policy process. Published: 1 January 2017 by Edward Elgar Publishing in Business, Organized Labour and Climate Policy Business, Organized Labour and Climate Policy pp 22-46.

9. Foster, J. (2002) Ecology against Capitalism. Monthly Review. New York. 